\title{
Gender and website design in e-business
}

\section{Dianne Cyr* and Carole Bonanni}

\author{
Simon Fraser University \\ 15th Floor Central City Tower \\ 13450 102nd Avenue \\ Surrey, B.C. V3T 5X3, Canada \\ Fax: 604.268.7485 \\ E-mail: cyr@sfu.ca \\ E-mail: carole_bonanni@sfu.ca \\ *Corresponding author
}

\begin{abstract}
Although online shopping has increased exponentially in recent years, very little is known about the difference in male and female perceptions of this experience. This investigation is focused on examining how perceptions between the genders differ concerning transaction security, website design elements, and how the experience of online shopping results in perceptions of website trust, website satisfaction, and e-loyalty. Results of the research indicate that transaction security was not as large a concern as expected, and perceptions about it did not differ between men and women. Alternately, in support of the research hypotheses, there are significant differences in perceptions of website design and website satisfaction between the genders, but not for e-loyalty.
\end{abstract}

Keywords: website trust; website satisfaction; website design; e-loyalty; gender; e-business.

Reference to this paper should be made as follows: Cyr, D. and Bonanni, C. (2005) 'Gender and website design in e-business', Int. J. Electronic Business, Vol. 3, No. 6, pp.565-582.

Biographical notes: Dianne Cyr is Associate Professor in the Faculty of Business at Simon Fraser University in Vancouver. She is currently leading a SSHRC-funded research project titled 'Managing E-loyalty through Experience Design'. This investigation is focused on how trust, satisfaction, and loyalty are built in online business environments through website design. A unique feature of this work is comparisons across cultures. Further details of this project may be accessed at www.eloyalty.ca. She is the author of five books and over 40 articles. Further career details may be found at www.diannecyr.com.

Carole Bonanni is Assistant Professor at Simon Fraser University. Her current research interests are in the areas of web design across cultures, m-banking, industrial organisation and competitive strategy. Dr. Bonanni is currently involved in two research projects: 'Managing E-loyalty through Experience Design', and 'Simulation Games for the Telecommunications Industry'.

A version of this paper was previously presented at the 6th World Congress on the Management of Electronic Business, 19-21 January, Hamilton, Ontario. 


\title{
1 Introduction
}

The incidence of women shopping online is gradually increasing, although relatively little is known about gender differences when buying on the web. According to Dittmar et al. (2004,p.423):
"Given that men and women have been shown to differ in their attitudes toward both the Internet and shopping (in conventional environments), it seems surprising that there is little research that explicitly addresses gender differences in on-line buying."

Prior research that does examine gender-related attitudes and activities on the internet suggests that women, more than men, are less interested in the internet, spend less time online than men, and are less likely to purchase online (Allen, 2001; Garbarino and Strahilevitz, 2004; Rodgers and Harris, 2003).

It is expected that the design of the website may have an impact on user preferences, which in turn may produce differing reactions between men and women. Chen and Dhillon (2002,pp.310-311) write:

\begin{abstract}
"In the case of an internet vendor, the website is perhaps the only way a firm communicates with its customers. Therefore, its appearance and structure encourage or discourage a consumer's purchase intentions. In the marketing literature, website features such as layout, appeal, graphics, readability, and ease-of-use have been considered to affect consumers' clicking frequency."
\end{abstract}

However, to our knowledge, the impact of gender in relation to website design is considered in only one investigation (Simon, 2001). This suggests a need for further investigations in this area.

Although trust and satisfaction (Anderson and Srinivasan, 2003; Devaraj et al., 2002; Szymanski and Hise, 2000; Yoon, 2002) are expected to be precursors to e-loyalty, few studies have systematically examined these elements in relation to user design preferences. More specifically, design preferences contributing to the development of trust, satisfaction and e-loyalty have rarely been examined with respect to gender.

This investigation addresses this gap in the research, and proposes a comparison between male and female website users' website design preferences, and their subsequent perceptions of trust, satisfaction and e-loyalty. The implications of this research are important as an exploratory step for understanding the role of design and gender in relation to e-loyalty.

In this paper, a review of the literature emphasises design, trust, satisfaction, and e-loyalty with reference to gender. Various related hypotheses for testing are outlined, and the results of a survey, conducted with university students in Canada, is reported. The paper concludes with an interpretation of the findings, and directions for future investigations.

\section{Website trust, website satisfaction and e-loyalty}

"Since transactions [on the internet] occur without personal contact, consumers are generally concerned with legitimacy of the vendor and authenticity of products or services" (Chen and Dhillon, 2002,p.1). Trust focuses on consumer confidence in the website as part of a buyer-seller transactional exchange, and consumer's "willingness to 
rely on the seller and take actions in circumstances where such action makes the consumer vulnerable to the seller" (Jarvenpaa et al., 1999,p.4). In contrast, website satisfaction refers to a positive navigation experience and perception of a well-designed website (Balasubramanian et al., 2003; Solomon et al., 1996). Generally accepted in other work, and also adopted as a definition in this research, e-loyalty represents online repeat purchase intention or return visits to a website (Szymanski and Hise, 2000; Corstjens and Lal, 2000; Cyr et al., 2005; Cyr et al., 2004; Gommans et al., 2001). ${ }^{1}$

\title{
2.1 Website trust
}

Prior to the advent of the internet, trust was examined in multiple disciplines in multiple ways. Traditionally, trust has been difficult to define and measure (Rousseau et al., 1998). Other researchers have called the state of trust definitions confusing (Lewis and Weigert, 1985; McKnight et al., 2002), a 'conceptual morass' (Carnevale and Wechler, 1992,p.473) and multi-dimensional (Chen and Dhillon, 2002; Rousseau et al., 1998; Mayer et al., 1995). Others believe trust is a single dimension (Selnes, 1998). Bhattachherjee (2002,p.219) conducted an extensive review of trust based on previous research and concludes that ability, benevolence and integrity are conceptually distinct and reflect 'different elements of cognitive and affective abstractions of trust'.

Disposition to trust is an enduring and personal characteristic. According to McKnight et al. (2002,p.473), "Disposition to trust is a general, i.e. not situation-specific, inclination to display faith in humanity or to adopt a trusting stance towards others". Further:

\begin{abstract}
"[T]rust is determined by a general trusting disposition that is the product of a lifelong socialization process. This disposition is especially influential when the trusting party has not had extensive personal interaction with the specific organization or person in question. Therefore, also a trusting disposition should influence people's trust in a vendor." (Gefen and Straub, 2000,p.729)
\end{abstract}

"Lack of trust is one of the most frequently cited reasons for consumers not purchasing from Internet vendors" (Grabner-Krauter and Kaluscha, 2003). Despite the importance of the concept, a definition of trust in online environments remains as elusive as does a definition of trust when conducting traditional shopping.

With reference to gender and e-business, few studies focus on disposition to trust, perceived transaction security, and users' perceptions of website trust. Noteworthy, Garbarino and Strahilevitz (2004,p.768) found that 'women perceive a higher level of risk in online purchasing than do men'. Rodgers and Harris (2003,p.326) considered gender in e-commerce with an aim to explain why women were less interested in online shopping than men. The authors found 'women did not trust e-commerce to the same extent as men did'. In other works, gender differences in online shopping were investigated, and findings further confirm that women are less trusting of web shopping and web-based activities in general (Wells and Chen, 1999). This results in the following hypothesis as tested in this investigation.

\section{Hypothesis $1 \quad$ Women, more than men, will exhibit less website trust.}

With reference to online buying, both men and women express concerns about security of transactions and express doubts about credit card security (Dittmar et al., 2004). 
Hypothesis 2 There will be no difference between men and women regarding attitudes toward transaction security, and both genders will express concerns about security when shopping online.

\subsection{Website satisfaction}

Customer satisfaction has typically been studied in physical environments. In contrast, website satisfaction relates to 'stickiness' and 'the sum of all the website qualities that induce visitors to remain at the website rather than move to another site' (Holland and Menzel-Baker, 2001,p.37). According to Anderson and Srinivasan (2003), e-satisfaction is defined as the contentment of the customer with respect to his or her prior purchasing experience with a given online vendor. A positive navigation experience and perception of a well-designed site may result in consumer e-satisfaction (Agarwal and Venkatesh, 2002; Fogg et al., 2002; Hoffman and Novak, 1996; Nielsen, 2001).

Koufaris (2002) uniquely combines elements of the Technology Acceptance Model (TAM), with marketing and consumer behaviour when examining web users' behaviour. The results of the investigation suggest that characteristics, such as involvement with a product, level of web skills of the consumer, value-added search mechanisms, and the challenge to perform to the best of one's ability will result in perceived usefulness and perceived ease of use (as in TAM), as well as shopping enjoyment. However, Dittmar et al. (2004,p.326) outline the computer environment as being seen as 'masculine', which may lead women to feel some sense of disempowerment. In fact, in this investigation, the authors found that 'men also reported a more satisfying online shopping experience than women did'. Another study confirms that women report less computer self-efficacy and more anxiety when using a computer, which presumably lessens satisfaction with computer use, and by association, with enjoyment of online shopping (Jackson et al., 2001). Finally, males had higher levels of satisfaction with the websites tested than did females (Simon, 2001).

As a result of the preceding, the following hypothesis is suggested.

\section{Hypothesis $3 \quad$ Women, more than men, will exhibit less website satisfaction.}

\subsection{E-Loyalty}

In studies on the internet, there is some evidence to suggest that if users are satisfied with a website, including its design, then they are more likely to revisit the site or re-purchase from it resulting in online loyalty, or e-loyalty (Anderson and Srinivasan, 2003; Devaraj et al., 2002; Gommans et al., 2001). In a recent study by Flavián et al. (2005), trust of the user increased when the website system was perceived as usable, which in turn resulted in e-loyal behaviour.

To date, we know of no work that specifically examines web user loyalty across genders. However, prior research examining risk perceptions in marketing found that risk perceptions are negatively correlated with willingness to buy (Shimp and Bearden, 1982; White and Truly, 1989). As already noted, Garbarino and Strahilevitz (2004), found that women perceived online shopping to have higher levels of risk than did men. The following hypothesis is offered. 
Hypothesis $4 \quad$ Women, more than men, will exhibit less loyalty to a website.

\section{Website design}

Effective website design engages and attracts online consumers (Agarwal and Venkatesh, 2002; Hui and Triandis, 1985; Morgan and Hunt, 1994). According to Gommans et al. (2001,p.51), "A website has to be designed for a targeted customer segment..." Chau et al. (2000) argue that the modes of information presented on the internet, and the quality of graphics have a significant impact on user experience. Research in design suggests various guidelines for effective web navigation (Farkas and Farkas, 2000), criteria for optimal web design (Bernard, 2002; Egger, 2001), and how aesthetics and usability might be linked (Trackinsy, 1997).

Of particular relevance to this research, Garrett (2003) suggests six classifications for user experience (visual design, information architecture, information design, navigation design, content and interaction design). Of these classifications, three were selected as outlined below, and frame the survey design questions in the current investigation. These categories were selected as they are also represented in other recent work in this field. They include:

- Information design

Elements of the site that convey accurate or inaccurate information to a user. For instance, the location of an icon on the screen would be the domain of information architecture, but whether or not that icon conveys the right information to a user is the domain of information design.

- Navigation design

The navigational scheme used to help or hinder users as they access different sections of the site.

- Visual design

Elements that deal with the balance, emotional appeal, aesthetics and uniformity of overall website graphical look. This includes colours, photographs, shapes, font types and animations.

It appears that a number of design characteristics contribute to the users' experience of a website. However, preferences for design characteristics have not generally been tested between men and women. In one investigation by Simon (2001), differences in website preferences are examined between men and women. More specifically, Simon tests perception of a site, which refers to information richness, communication effectiveness, and communication interface (and the actions required by the user to activate and use the channel). Findings from this investigation reveal that overall, women have a lower perception of websites than do men. It should be noted however, that the categories used by Simon differ from design characteristics used by other researchers, and do not explicitly include the categories outlined by Garrett (2003).

Based on the paucity of information as to how men and women react to design elements of a website, the following exploratory hypothesis is suggested. 
Hypothesis $5 \quad$ There will be differences between men and women in relation to their perception of the website for each of the design elements (information design, navigation design and visual design).

\section{Methodology for the study}

\subsection{Survey development}

A survey instrument was constructed to test user reactions to a website task. Survey categories include: transaction security, information design, navigation design, visual design, website trust, website satisfaction and e-loyalty. Items on transaction security were adapted from Grewal et al. (2003). Items on design are in categories as identified by Garrett (2003) and outlined in the previous section. Design items relate to work by Marcus and Gould (2000), Egger (2001), Badre (2000), and Cheskin Research Group (1999; 2000). Items on trust and satisfaction are drawn from Yoon (2002) and Gefen and Straub (2000). The survey was validated by Cyr et al. (2005; Cyr et al., 2004) in earlier works. All items are constructed as agree-disagree statements on a 5-point Likert scale. The survey items appear in the Appendix.

\subsection{Research task and procedure}

Undergraduate students at a Canadian university were solicited to complete an online survey via a posting in a course forum. After an extensive search for a website, which has also been used in our other work, participants in the study were asked to navigate the Canadian Sony shopping website ${ }^{2}$ to choose a digital camera they would hypothetically purchase. The experimental task is to navigate the site to find and select a digital camera. Once the product has been chosen, students proceed to the online checkout, and the task is completed at the point where they are required to enter personal information as a first step in the purchase process. Following the task, subjects completed an online questionnaire. Students were allowed to complete the questionnaire only once. Open-ended questions were also posed to gather qualitative information about the shopping experience.

\subsection{Participants}

One hundred twenty undergraduate students were provided information about the online survey, and 76 students volunteered to participate. The approach of soliciting students as participants is common in this field of research, and according to Grabner-Krauter and Kaluscha (2003), most studies in e-commerce utilise undergraduate or MBA students. The ratio of women-to-men is approximately 1:2, with 26 female respondents and 49 male respondents. The unequal distribution of participant is not uncommon, and is similar to the approach used by van Iwaarden et al. (2004). Students in this investigation were comfortable with the format of the online task, and the survey was administered through a learning technology with which they had previous experience to complete online tests, assess their peers and evaluate their instructors. 
Based on demographic data collected at the end of the survey, participants were familiar with using the internet. They spent an average of 32 hours a week online (mostly to complete homework), and $98.7 \%$ have high-speed internet connection at home. Fifty percent use online banking. However, participants did not have extensive experience buying online. On average, they had made two previous online purchases, and $54 \%$ have never bought online. This may be explained by the fact that only $12 \%$ of the participants were over 20 years of age, and therefore may not have access to a credit card usually required for online purchases.

\section{Results}

The objective of this exploratory research is to determine whether there are differences between genders regarding attitudes towards transaction security, preferred website design elements, website trust, website satisfaction and website loyalty. To determine differences, t-tests were run on the individually observed variables within each of the following factors: Transaction Security, Information Design, Navigation Design, Visual Design, Trust, Satisfaction and E-loyalty. Convergent validity of the proposed constructs is verified. The approach followed is consistent with other researchers (Fornell and Larcker, 1981; Hassanein and Head, 2004). Three measures are examined:

1 item loadings

2 alpha scores

3 average variance extracted.

As shown in Table 1, values of the item loadings confirm that all items in each factor load highly on their respective factors. According to Hair et al. (1995), with 76 observations, an item is significant if its factor loading is greater than 0.60. From the original 23 variables, none had to be eliminated. Construct reliability was assessed using Cronbach alphas. The alphas were acceptable as they were between 0.683 and 0.865 . Alphas should be greater than 0.5 (Rivard and Huff, 1988). Lastly, the average variance extracted from each construct is greater than 0.5 (Fornell and Larcker, 1981). In conclusion, the three measures reported confirm that the proposed constructs demonstrate convergent validity.

The correlation matrix approach was applied to evaluate discriminant validity. Discriminant validity refers to a lower correlation level with items from other dimension than with items from the same construct. Discriminant validity for each item was tested by counting the number of instances the item correlates higher with items of other factors than with items of its own theoretical factor. For discriminant validity, Campbell and Fiske (1959) suggest the count should be fewer than one-half the potential comparisons. Only 24 violations of discriminant validity were reported from a pool of 484 comparisons. 
Table 1 Convergent validity measures

\begin{tabular}{|c|c|c|c|}
\hline Factors & Item loadings & Alphas & Average variance extracted \\
\hline Transaction Security (TS) & & 0.865 & 0.788 \\
\hline TS1 & 0.837 & & \\
\hline TS1 & 0.812 & & \\
\hline TS2 & 0.805 & & \\
\hline Information Design (ID) & & 0.812 & 0.731 \\
\hline ID1 & 0.857 & & \\
\hline ID2 & 0.853 & & \\
\hline ID3 & 0.855 & & \\
\hline Navigation Design (ND) & & 0.805 & 0.721 \\
\hline ND1 & 0.860 & & \\
\hline ND2 & 0.826 & & \\
\hline ND3 & 0.861 & & \\
\hline Visual Design (VD) & & 0.733 & 0.560 \\
\hline VD1 & 0.741 & & \\
\hline VD2 & 0.740 & & \\
\hline VD3 & 0.749 & & \\
\hline VD4 & 0.762 & & \\
\hline Website Trust (TR) & & 0.839 & 0.760 \\
\hline Trust1 & 0.922 & & \\
\hline Trust2 & 0.827 & & \\
\hline Trust3 & 0.863 & & \\
\hline Website Satisfaction (SAT) & & 0.754 & 0.583 \\
\hline Sat1 & 0.616 & & \\
\hline Sat2 & 0.843 & & \\
\hline Sat3 & 0.841 & & \\
\hline Sat4 & 0.731 & & \\
\hline Loyalty (LOY) & & 0.683 & 0.760 \\
\hline Loy1 & 0.871 & & \\
\hline Loy2 & 0.871 & & \\
\hline
\end{tabular}

Note: Using principal component analysis (Varimax with Kaiser normalisation)

\subsection{Website trust, satisfaction and e-loyalty across genders}

Website trust, satisfaction, e-loyalty, and attitudes toward transaction security were investigated between men and women to determine if there were systematic differences regarding their perceptions of a website. No statistical differences between genders were reported with a MANOVA analysis for trust, attitude toward transaction security and e-loyalty when using factor scores as the independent variables. Statistically significant results are reported for satisfaction with the MANOVA analysis. As such, Hypothesis 1 suggesting women are less trusting of websites than men is rejected. Refer to Table 2. 
Table 2 Website trust, satisfaction and e-loyalty for men and women - MANOVA analysis

\begin{tabular}{|c|c|c|c|c|c|c|}
\hline Source & Dependent variable & Type III SS & $d f$ & $M S$ & $F$ & Sig \\
\hline \multirow[t]{4}{*}{ Corrected model } & Transactions & $0.810(a)$ & 1 & 0.81 & 0.81 & 0.372 \\
\hline & Trust & 2.61(b) & 1 & 2.61 & 2.65 & 0.108 \\
\hline & Satisfaction & 4.29(c) & 1 & 4.28 & 4.43 & 0.039 \\
\hline & Loyalty & $0.47(d)$ & 1 & 0.47 & 0.48 & 0.491 \\
\hline \multirow[t]{4}{*}{ Intercept } & Transactions & 0.03 & 1 & 0.03 & 0.03 & 0.869 \\
\hline & Trust & 0.19 & 1 & 0.19 & 0.19 & 0.666 \\
\hline & Satisfaction & 0.37 & 1 & 0.37 & 0.38 & 0.537 \\
\hline & Loyalty & 0.13 & 1 & 0.13 & 0.14 & 0.713 \\
\hline \multirow[t]{4}{*}{ Gender } & Transactions & 0.81 & 1 & 0.81 & 0.81 & 0.372 \\
\hline & Trust & 2.61 & 1 & 2.6 & 2.65 & 0.108 \\
\hline & Satisfaction & 4.29 & 1 & 4.29 & 4.43 & 0.039 \\
\hline & Loyalty & 0.47 & 1 & 0.47 & 0.48 & 0.491 \\
\hline \multirow[t]{4}{*}{ Error } & Transactions & 73.16 & 73 & 1.00 & & \\
\hline & Trust & 72.03 & 73 & 0.99 & & \\
\hline & Satisfaction & 70.66 & 73 & 0.97 & & \\
\hline & Loyalty & 72.48 & 73 & 0.99 & & \\
\hline \multirow[t]{4}{*}{ Total } & Transactions & 73.99 & 75 & & & \\
\hline & Trust & 74.65 & 75 & & & \\
\hline & Satisfaction & 74.95 & 75 & & & \\
\hline & Loyalty & 72.98 & 75 & & & \\
\hline \multirow[t]{4}{*}{ Corrected total } & Transactions & 73.97 & 74 & & & \\
\hline & Trust & 74.65 & 74 & & & \\
\hline & Satisfaction & 74.95 & 74 & & & \\
\hline & Loyalty & 72.96 & 74 & & & \\
\hline
\end{tabular}

Notes: $\quad$ a R2 $=0.011$ (Adjusted R2 $=-0.003$ )

$$
\begin{aligned}
& \text { b R2 }=0.035 \text { (Adjusted R2 }=0.022) \\
& \text { c R2 }=0.057 \text { (Adjusted R2 }=0.044) \\
& \text { d R2 }=0.007 \text { (Adjusted R2 }=-0.007)
\end{aligned}
$$

However, t-tests comparing trust levels for men and women yield a slightly different picture. Overall, women were less likely to trust the website. When examining each trust item, mean scores for women are lower than scores for men. Statistically significant differences were found between men and women regarding ability to trust information presented on the site, with women less trusting than men. When women were asked what they would change about the website, they mentioned they would like more information about the product, and greater privacy. Refer to Table 3. 
Table 3 Website trust, satisfaction and e-loyalty for men and women - t-tests

\begin{tabular}{llll}
\hline & Men & Women & T-test \\
\hline Trust (Hypothesis 1) & & & \\
$\quad$ Trust website & 3.96 & 3.58 & 1.65 \\
$\quad$ Trust information presented on website & 4.18 & 3.73 & $1.93^{*}$ \\
$\quad$ Trust transaction process & 3.71 & 3.54 & 0.69 \\
$\quad$ Transaction security (Hypothesis 2) & 3.90 & 3.77 & 0.47 \\
$\quad$ Believe credit card information secure & 3.61 & 3.35 & 1.06 \\
$\quad$ Believe transaction is secure & 3.94 & 3.58 & 1.66 \\
$\quad$ Third-party assurance seal & & & \\
Satisfaction (Hypothesis 3) & 3.98 & 3.50 & $2.09 * *$ \\
$\quad$ Website appeals to me visually & 3.90 & 3.50 & $1.79 *$ \\
$\quad$ Website fulfils personal needs and expectations & 3.86 & 3.58 & 1.27 \\
$\quad$ Website satisfies my needs & 4.18 & 3.85 & 1.41 \\
$\quad$ Using site/service is satisfactory & & & 1.09 \\
E-loyalty (Hypothesis 4) & 3.55 & 3.27 & 0.122 \\
$\quad$ Would consider purchasing from website in future & 3.88 & 3.85 & \\
$\quad$ Would visit website again &
\end{tabular}

Notes: *Significant at $0.1, * *$ significant at 0.05

Hypothesis 1: Women, more than men, will exhibit less website trust.

Hypothesis 2: There will be no difference between men and women regarding attitudes toward transaction security, and both genders will express concerns about security when shopping online.

Hypothesis 3: Women, more than men, will exhibit less website satisfaction.

Hypothesis 4: Women, more than men, will exhibit less loyalty to a website.

Regarding transaction security, and consistent with Hypothesis 2, no differences were detected across genders using t-tests. This finding is in alignment with the MANOVA analysis. However, contrary to expectations, men and women do not generally express concern about transaction security. As one respondent mentioned,

"I have confidence that any major brand would have a secure site to process transactions. Also, Mastercard and VISA always have their chargeback services, where if you didn't get something that is on the bill you can charge it back! Now that is security."

Also in Table 3, t-test scores for satisfaction and loyalty are reported. Consistent with the MANOVA analysis, statistically significant differences are found between men and women for satisfaction. In particular, men find the Sony website more appealing and able to fulfil more of their personal needs than women. Hypothesis 3 is supported. Regarding e-loyalty, there are no differences between men and women with respect to the intentions to purchase from the site in the future or revisit the SonyStyle website. Surprisingly, even if men, compared to women, seemed to be more satisfied and more trusting towards information provided on the website, this does not result in a higher probability of revisiting the website compared to women. Hence, Hypothesis 4 is rejected. 
Further observed in Table 3, men and women report mean item values above three. Therefore, they tend to trust the transaction process, trust the website, are satisfied with the website, and will tend to revisit the website. However, women report systematically lower averages than men.

\title{
5.2 Website design preferences across genders
}

In partial support of Hypothesis 5, a MANOVA analysis demonstrates there are differences between men and women regarding their attitude towards information design. Refer to Table 4.

Table 5 further compares website design preferences between men and women. On a Likert scale (1 to 5), mean scores for each design element are above three, suggesting both genders somewhat like the design of the Sony website. Women systematically report values lower than men, indicating they are less pleased with the Sony website.

T-tests reported in Table 5 for each individual item confirm to a certain degree the findings from the MANOVA analysis. Several differences are evident between men and women regarding their perception of the website, and five of 11 design items are statistically different using t-test comparisons.

Concerning information design, more men than women, reported the site to be better organised, and had more favourable impressions of how product information was presented. One female student notes:

\begin{abstract}
"Make it less busy in its design. Right now, there is a lot happening on the page, and the eye keeps wandering to other places on the page. It needs less flashy gimmicks and should be a bit more simple. For example, when looking at products, there is so much other stuff going on, such as other links, options and so forth. It is hard to concentrate on what you are looking for without wandering off to another section."
\end{abstract}

With reference to navigation design, men were more satisfied than women. A female student pointed out the SonyStyle website is "a little bit hard to navigate if you are new with the internet". Alternately, male respondents reported:

\footnotetext{
"The organization of navigation menu's and buttons is well laid out and thought out which allows easy navigation to any product they sell. Lots of pictures of the products is great when buying the camera, because you get to see every aspect of it which is good when deciding to buy the camera."

"I found it very easy to navigate throughout the website and find the information I was seeking. Immediately, I was able to locate where the digital camera section was, and browse through each camera's specs and compare them among each other. The mapping of the site was quite good in that there were various ways and routes to getting to certain pages other than just the main navigation menu on the left. From the tabs when viewing cameras, were links which lead to relevant accessories, comparable cameras, legal information and info on free shipping."
} 
Table 4 Website design preferences for men and women - MANOVA analysis

\begin{tabular}{|c|c|c|c|c|c|c|}
\hline Source & $\begin{array}{l}\text { Dependent } \\
\text { variable }\end{array}$ & $\begin{array}{c}\text { Type III sum of } \\
\text { squares }\end{array}$ & $d f$ & Mean square & $F$ & Sig \\
\hline \multicolumn{7}{|c|}{ Corrected model } \\
\hline & InfoDesign & $4.15(a)$ & 1 & 4.15 & 4.32 & 0.041 \\
\hline & NavigDesign & $2.62(b)$ & 1 & 2.62 & 2.69 & 0.106 \\
\hline & VisDesign & $2.19(\mathrm{c})$ & 1 & 2.19 & 2.24 & 0.139 \\
\hline \multicolumn{7}{|c|}{ Intercept } \\
\hline & InfoDesign & 0.28 & 1 & 0.28 & 0.29 & 0.589 \\
\hline & NavigDesign & 0.145 & 1 & 0.15 & 0.15 & 0.698 \\
\hline & VisDesign & 0.11 & 1 & 0.11 & 0.11 & 0.742 \\
\hline \multicolumn{7}{|l|}{ Gender } \\
\hline & InfoDesign & 4.15 & 1 & 4.15 & 4.32 & 0.041 \\
\hline & NavigDesign & 2.62 & 1 & 2.62 & 2.69 & 0.106 \\
\hline & VisDesign & 2.19 & 1 & 2.19 & 2.24 & 0.139 \\
\hline \multicolumn{7}{|l|}{ Error } \\
\hline & InfoDesign & 70.12 & 73 & 0.96 & & \\
\hline & NavigDesign & 71.34 & 73 & 0.98 & & \\
\hline & VisDesign & 71.47 & 73 & 0.98 & & \\
\hline \multicolumn{7}{|l|}{ Total } \\
\hline & InfoDesign & 74.28 & 75 & & & \\
\hline & NavigDesign & 73.98 & 75 & & & \\
\hline & VisDesign & 73.68 & 75 & & & \\
\hline \multicolumn{7}{|c|}{ Corrected total } \\
\hline & InfoDesign & 74.28 & 74 & & & \\
\hline & NavigDesign & 73.97 & 74 & & & \\
\hline & VisDesign & 73.66 & 74 & & & \\
\hline
\end{tabular}

Notes: $\quad$ a R2 $=0.056$ (Adjusted R2 $=0.043$ )

b R2 $=0.035$ (Adjusted R2 $=0.022$ )

c R2 $=0.030$ (Adjusted R2 $=0.016$ )

Finally, in the realm of visual design, significant differences on t-tests occurred between the genders regarding the degree of interaction with the site, and whether animations were considered meaningful. Women were more attracted by the colours on the site, and men by the interactive and 'flashy' aspects of the site. Some of these sentiments are captured in the following statements:

Female: "I really liked the design and the colors used to attract potential customers. The design helped assure me that it is a professionally designed website."

Male: "It [the website] had an interesting, flashy yet refined layout. It displayed/presented the cameras in an attractive manner. The actual buying process was relatively straightforward, quick and easy to use."

Male: "I liked the interactive interface. It is well presented. The site appears to be professionally created. It is very easy to navigate." 
Table 5 Website design preferences for men and women - t-tests

\begin{tabular}{llll}
\hline & Men & Women & T-test \\
\hline Information design & & & \\
$\quad$ Logical presentation & 4.10 & 3.85 & 1.21 \\
$\quad$ Well-organised & 4.37 & 4.00 & $1.71^{*}$ \\
$\quad$ Product info well-presented & 4.20 & 3.62 & $2.44^{* *}$ \\
Navigation design & & & \\
$\quad$ Easy to navigate & 4.45 & 3.85 & $2.75^{* *}$ \\
Easy to use & 4.26 & 4.07 & 0.76 \\
Good navigation facilities & 4.16 & 4.00 & 0.69 \\
Visual design & & & \\
$\quad$ Degree of interaction & 3.98 & 3.50 & $1.97^{*}$ \\
$\quad$ Tailored to specific needs & 3.88 & 3.58 & 1.33 \\
$\quad$ Professionally designed & 4.53 & 4.42 & 0.55 \\
$\quad$ Attractive screen design & 4.20 & 4.04 & 0.65 \\
$\quad$ Meaningful website animations & 3.69 & 3.04 & $2.95^{* * *}$ \\
\hline
\end{tabular}

Notes: $\quad *$ Significant at $0.1, * *$ significant at $0.05, * * *$ significant at 0.01 (2-tailed)

Hypothesis 5: There will be differences between men and women in relation to their perception of the website for each of the design elements (information design, navigation design and visual design).

\section{Interpretation and future research}

Although there is some evidence that men and women experience interaction on computers differently, research to examine these differences is sparse. Further, there is little to support the notion that differences exist between the perceptions of men and women when shopping online. Although some preliminary work examines trust, satisfaction, or online transaction security issues between men and women, to our knowledge, no previous research specifically examines e-loyalty. Further, with the exception of Simon (2001), previous work has not systematically examined gender differences in preferences for website design. Hence, this exploratory work represents a foray into a new area of research with respect to gender and the internet. The current work will be utilised to build a predictive model of gender differences for future testing.

Garbarino and Strahilevitz (2004) found that women experience higher levels of risk with online purchasing. In the present research, this trend was generally apparent, although not statistically significant. Only on the concern whether information on the website is trusted do women exhibit significantly lower scores than do men. This finding suggests that women are either more sceptical of information presented online, or require more information to make a purchasing decision. These results may also be associated with whether the user trusts the vendor's reputation. Although in this case, most would probably agree that Sony is a credible and established corporate entity. Related to trust and risk is the users' willingness to trust transactions on the website. As expected, in this investigation, no differences between men and women were found on this dimension. 
However, rather surprising, both genders indicated they are quite comfortable with the online transaction process. This may be related to the young age of respondents, and subsequently having few, if any, negative experiences with transaction on the internet. However, this reaction may also indicate that many security concerns are already addressed by online vendors, especially through the use of security symbols and safeguards on the website.

Both men and women reported moderate satisfaction with the SonyStyle website, with men, overall, more satisfied with the site. In particular, men reported that using the site is satisfactory (scoring 4.19 out of 5), which confirms the earlier work by Simon (2001). Two areas in which men had statistically significant different responses from women were in the visual appeal of the website, and in the site's ability to fulfil personal needs and expectations. In each case, website designers will need to more carefully examine the exact elements of websites that result in these different responses. With the increased numbers of women shopping online, a better understanding of women's requirements will also have commercial value.

It is interesting that although men appear to be more trusting and satisfied with the website, this does not translate into an interest to consider purchasing on the website in the future, or revisiting the site. Hence, there are no significant differences on the e-loyalty dimension between men and women.

One area that has received almost no attention to date, elicited many significant gender differences as a result of the current investigation. Website design is an important differentiator for how men or women perceive the online shopping experience. In fact, in five of the 11 design items, significant differences in perceptions exist between men and women. And, for every design item, the men had a higher opinion of the website than did the women. In the area of information design, women did not perceive the site to be as well organised as men did. Men, more than women, perceived product information to be well presented. Although not confirmed, it may be that men and women prefer online information to be presented in different ways. Further, women were significantly less satisfied than men with the navigation of the site. This suggests a need to better understand the needs of women in order to navigate and find product or service information on websites. Finally, in the area of visual design, the most significant differences between the genders occurred in the degree of interaction with the site, and whether or not animations are perceived as meaningful. In each case, women were again less satisfied. Overall, it is clear that website design is an important feature of the website, and that clear differences regarding perceptions on design occur between men and women. This also heralds a call for future researchers, as well as website designers, to place greater attention to design that is considered favourable to both genders.

This study is not without limitations. The website used in the investigation belongs to Sony, which is a well-known brand. As such, the Sony name may elicit brand and product associations for the user. Ideally, similar studies should be conducted with a wider range of websites. Further, the research was conducted with a sample of students from a university based in Western Canada. To add greater generalisability to this work, a larger and more diversified sample of participants is required.

Since the current avenue of investigation of website preferences and the online shopping experience between men and women is relatively new, there is much scope for future investigations in this field. Further research is suggested to more deeply probe online trust, transaction security, satisfaction, and e-loyalty. In addition, differences in design preferences for men and women indicate that this area offers multiple 
opportunities to expand understanding as to what is gender-relevant when browsing or shopping online. In the area of cultural differences on the internet, previous research indicates that localisation of web content is important to unique constituents (Cyr et al., 2004; Cyr et al., 2005; Egger, 2001). A match of website characteristics to cultural preferences and sensitivities is, in fact, critical to building relationships in an environment where buyers and sellers are without personal contact. It may be that better understanding of gender preferences on the web is the new vanguard of localisation for the internet.

\section{Acknowledgement}

This research is part of a three-year project titled 'Managing E-Loyalty through Experience Design' generously funded by a Social Sciences and Humanities Research Council of Canada grant under the special category 'Initiative on the New Economy'.

\section{References}

Agarwal, R. and Venkatesh, V. (2002) 'Assessing a firm's web presence: a heuristic evaluation procedure for measurement of usability', Information Management Research, Vol. 13, No. 2, pp.168-121.

Allen, D. (2001) Women on the Web, http://www.emarketer.com/analysis/ecommerce_b2c/ 20010228_b2c.html.

Anderson, R.E. and Srinivasan, S.S. (2003) 'E-satisfaction and e-loyalty: a contingency framework', Psychology and Marketing, Vol. 20, No. 2, pp.123-138.

Badre, A.N. (2000) 'The effects of cross cultural interface design orientation on World Wide Web user performance', GVE Research Technical Reports, http://www.cc.gatech.edu/gvu/reports/ 2001/abstracts/01-03.html (accessed 24 April 2001).

Balasubramanian, S., Konana, P. and Menon, N.M. (2003) 'Customer satisfaction in virtual environments: a study of online investing', Management Science, Vol. 49, No. 7, pp.871-889.

Battachherjee, A. (2002) 'Individual trust in online firms: scale development and initial test', Journal of Management Information Systems, Vol. 19, No. 1, pp.211-241.

Bernard, M. (2002) Criteria for Optimal Web Design (Designing for Usability), http://psychology.wichita.edu/optimalweb/print.htm (accessed 10 June 2002).

Campbell, R. and Fiske, D.W. (1959) 'Convergent and discriminant validation by multitrait-multimethod matrix', Psychological Bulletin, Vol. 56, No. 2, pp.81-105.

Carnevale, D.G. and Wechler, B. (1992) 'Trust in the public sector: individual and organizational determinants', Administrative Sociology, Vol. 23, pp.471-494.

Chau, P.K., Au, G. and Tam, K.Y. (2000) 'Impact of information presentation modes on online shopping: an empirical evaluation of a broadband interactive shopping service', Journal of Organizational Computing Electronic Commerce, Vol. 10, No. 1, pp.1-22.

Chen, S.C. and Dhillon, G.S. (2002) 'Interpreting dimensions of consumer trust in e-commerce', Information Management and Technology, Vol. 4, pp.303-318.

Cheskin Research Group (1999) eCommerce Trust Study, http://www.cheskin.com/think/studies/ ecomtrust.html (accessed 22 April 2002).

Cheskin Research Group (2000) Trust in the Wired Americas, At http://www.cheskin.com/think/ studies/trust2.html (accessed 24 April 2001).

Corstjens, M. and Lal, R. (2000) 'Building store loyalty through store brands', Journal of Marketing Research, Vol. 37, No. 3, pp.281-292. 
Cyr, D., Bonanni, C. and Ilsever, J. (2004) 'Design and e-loyalty across cultures in electronic commerce', Proceedings for the Sixth International Conference on Electronic Commerce (ICEC04), Association for Computing Machinery (ACM), ISBN 1-58113-930-6.

Cyr, D., Bonanni, C., Bowes, J. and Ilsever, J. (2005) 'Beyond trust: website design preferences across cultures', Journal of Global Information Management, Vol. 13, No. 4, pp.24-52.

Devaraj, S., Fan, M. and Kohli, R. (2002) 'Antecedents of B2C channel satisfaction and preference: validating e-commerce metrics', Information Systems Research, Vol. 13, No. 3, pp.316-333.

Dittmar, H., Long, K. and Meek, R. (2004) 'Buying on the internet: gender difference in on-line and conventional buying motivations', Sex Roles, Vol. 50, Nos. 5-6, pp.423-444.

Doney, P.M. and Cannon, J.P. (1997) 'An examination of the nature of trust in buyer-seller relationships', Journal of Marketing, Vol. 61, No. 2, pp.35-51.

Egger, F.N. (2001) 'Affective design of e-commerce user interfaces: how to maximize perceived trustworthiness', Proceedings of the International Conference on Affective Human Factors Design, London Press.

Farkas, D.K. and Farkas, J.B. (2000) 'Guidelines for designing web navigation', Technical Communication, Third Quarter, pp.341-358.

Flavián, C., Guinalíu, M. and Gurrea, R. (2005) 'The role played by perceived usability, satisfaction and consumer trust on website loyalty', Information and Management, in press.

Fogg, B.J., Soohoo, C. and Danielson, D. (2002) 'How people evaluate a website's credibility? Results from a larger study', Persuasive Technology Lab, Stanford University www.consumerwebwatch.org/news/report3_credibilityresearch/stanfordPTL.pdf.

Fornell, C. and Larcker, D. (1981) 'Evaluating structural equation models with unobserved variables and measurement error', Journal of Marketing Research, Vol. 18, pp.39-50.

Garbarino, E. and Strahilevitz, M. (2004) 'Gender differences in the perceived risk of buying online and the effects of receiving a site recommendation', Journal of Business Research, Vol. 57, pp.768-775.

Garrett, J.J. (2003) The Elements of User Experience: User-centered Design for the Web, Indiana: New Riders Publications.

Gefen, D. and Straub, D. (2000) 'The relative important of perceived ease of use in IS adoption: a study of e-commerce adoption', Journal of Association of Information Systems, Vol. 1, No. 8, pp.1-30.

Gommans, M., Krishan, K.S. and Scheddold, K.B. (2001) 'From brand loyalty to e-loyalty: a conceptual framework', Journal of Economic and Social Research, Vol. 3, No. 1, pp.43-58.

Grabner-Krauter, S. and Kaluscha, E. (2003) 'Empirical research in online trust: a review and critical assessment', International Journal of Human-Computer Studies, Vol. 58, pp.783-812.

Grewal, G., Munger, J.L., Iyer, G.R. and Levy, J. (2003) 'The influence of internet retailing factors on price expectations', Psychology and Marketing, Vol. 20, No. 6, pp.477-493.

Hair, J.F., Anderson, R.E., Tatham, R.L. and Black, W.C. (1995) Multivariate Data Analysis with Readings, 4th ed., Englewoods Cliffs, NJ: Prentice-Hall.

Hassanein, K. and Head, M. (2004) 'Social presence through web interface and its impact on consumer attitude towards online shopping', Working Paper, McMaster e-Business Research Center, No. 10.

Hoffman, D.L. and Novak, T.P. (1996) 'Marketing in hypermedia computer-mediated environments: conceptual foundations', Journal of Marketing, Vol. 60, pp.50-68.

Holland, J. and Menzel-Baker, S. (2001) 'Customer participation in creating site brand loyalty', Journal of Interactive Marketing, Vol. 15, No. 4, pp.34-45.

Hui, C. and Triandis, H.C. (1985) 'Measurement in the cross-cultural psychology: a review and comparison of strategies', Journal of Cross-Cultural Psychology, Vol. 16, pp.131-152.

Van Iwaarden, J., van der Wiele, I., Ball, L. and Millen, R. (2004) 'Perceptions about the quality of web sites: a survey amongst students at Northeastern University and Erasmus University', Information and Management, Vol. 41, pp.947-995. 
Jackson, L.A., Ervin, K.S., Gardner, P.D. and Schmitt, N. (2001) 'Gender and the internet: women communicating and men searching', Sex Roles, Vol. 44, pp.363-379.

Jarvenpaa, S.L., Tractinsky, N., Saarinen, L. and Vitale, M. (1999) 'Consumer trust in an internet store: a cross-cultural validation', Journal of Computer Mediated Communication, Vol. 5, No. 2, http://www.ascusc.org/jcmc/vol5/issue2/jarvenpaa.html.

Koufaris, M. (2002) 'Applying the technology acceptance model and flow theory to online consumer behavior', Information Systems Research, Vol. 13, No. 2, pp.205-223.

Lewicki, R. and Bunker, B. (1995) 'Trust in relationships: a model of development and decline', in B.B. Bunker and J.Z. Rubin (Eds.) Conflict, Cooperation, and Justice, San Francisco: Jossey Bass, pp.133-173.

Lewis, D.J. and Weigert, A. (1985) 'Trust as a social reality', Social Forces, Vol. 63, pp.967-985.

McKnight, D.H., Choudhury, V.C. and Kacmar, C. (2002) 'Developing and validating trust measures for e-commerce: an integrative typology', Information Management Research, Vol. 13, No. 3, pp.334-359.

Marcus, A. and Gould, E.W. (2000) 'Cultural dimensions and global web user-interface design', Interactions, July-August, pp.33-46.

Mayer, R.C., Davis, J.H. and Schoorman, F.D. (1995) 'An integrative model of organizational trust', Academy of Management Review, Vol. 20, No. 3, pp.709-734.

Moorman, C., Deshpandé, R. and Zaltman, G. (1993) 'Factors affecting trust in market research relationships', Journal of Marketing, Vol. 57, pp.81-101.

Morgan, R.M. and Hunt, S.D. (1994) 'The commitment-trust theory of relationship marketing', Journal of Marketing, Vol. 58, pp.20-38.

Nielsen, J. (2001) Designing for Web Usability, Indiana: New Riders Publications.

Rivard, S. and Huff, S. (1988) 'Factors of success for end-user computing', Communications of the $A C M$, Vol. 31, No. 5, pp.552-561.

Rodgers, S. and Harris, M.A. (2003) 'Gender and e-commerce: an exploratory study', Journal of Advertising Research, September, pp.322-329.

Rousseau, D.M., Sitkin, S.M., Burt, R.S. and Camerer, C. (1998) 'Not so different after all: a cross-discipline view of trust', Academy of Management Review, Vol. 23, No. 3, pp.393-404.

Selnes, F. (1998) 'Antecedents and consequences of trust and satisfaction in buyer-seller relationship', European Journal of Marketing, Vol. 32, pp.305-322.

Shimp, T.A. and Bearden, W.O. (1982) 'Warranty and other extrinsic cue effects on consumers' risk perceptions', Journal of Consumer Research, Vol. 9, pp.38-46.

Simon, S.J. (2001) 'The impact of culture and gender on web sites: an empirical study', The Data Base for Advances in Information Systems, Vol. 32, No. 1, pp.18-37.

Solomon, M.R., Zaichkowsky, J.L. and Polegato, R. (1996) Consumer Behaviour: Buying, Having, and Being, Scarborough, ON: Prentice-Hall Canada, Inc.

Szymanski, D.A. and Hise, R.T. (2000) 'E-satisfaction: an initial examination', Journal of Retailing, Vol. 76, No. 3, pp.309-322.

Trackinsy, N. (1997) 'Aesthetics and apparent usability: empirically assessing cultural and methodological issues', CHI Proceedings.

Wells, W.D. and Chen, Q. (1999) 'Surfs up - differences between web surfers and non-surfers: theoretical and practical implications', in M.S. Roberts (Ed.) Proceedings of the Conference of the American Academy of Advertising, Gainsville, FL: University of Florida.

White, J.D. and Truly, E.L. (1989) 'Price-quality integration in warranty evaluation - a preliminary test of alternative models of risk assessment', Journal of Business Research, Vol. 19, pp.109-125.

Yoon, S-J. (2002) 'The antecedents and consequences of trust in online-purchase decisions', Journal of Interactive Marketing, Vol. 16, No. 2, pp.47-63. 


\section{Notes}

1 A thorough review of trust in non-online settings is not feasible within the scope of the present paper; however, the reader may wish to refer to the authors cited in this paragraph, as well as to (Morgan and Hunt, 1994; Doney and Cannon, 1997; Lewicki and Bunker, 1995; Moorman et al., 1993). In particular, Rousseau et al. (1998) present a comprehensive and cross-disciplinary critique of trust.

2 SonyStyle at http://www.sonystyle.ca

\section{Appendix Survey}

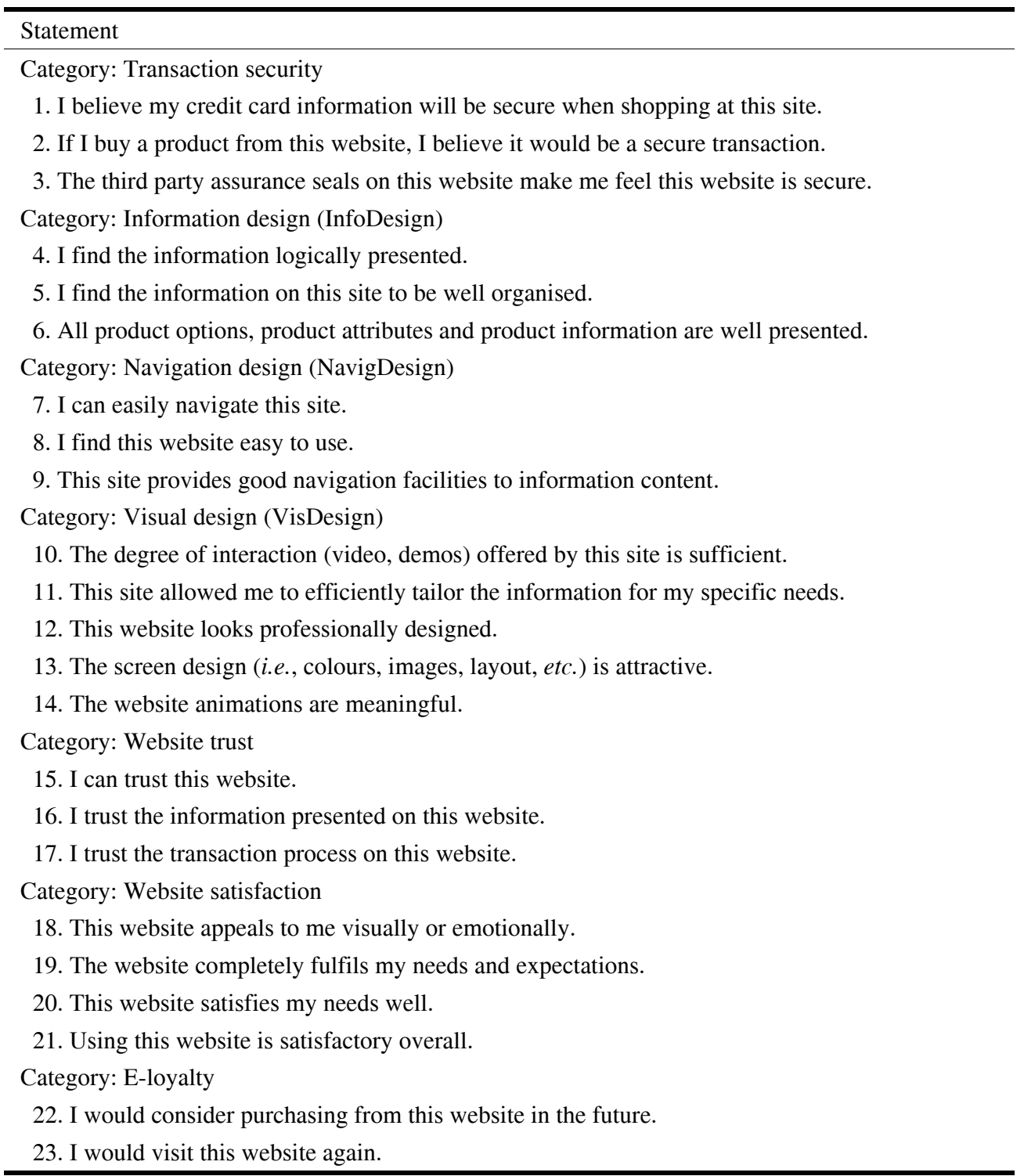

Note: Category titles have been added; items answered on a 5-point Likert scale 